\title{
ANALISIS INFORMASI PASAR KOMODITI MANGGA DI WILAYAH PERBATASAN INDONESIA MALAYSIA (SEBUAH KASUS DI DESA AJI KUNING KECAMATAN SEBATIK TENGAH )
}

\author{
COMMODITY MARKET INFORMATION ANALYSIS MANGO IN THE BORDER REGION OF \\ INDONESIA MALAYSIA (A CASE IN THE VILLAGE OF YELLOW AJI SUBDISTRICT SEBATIK)
}

\author{
Dewi Elviana ${ }^{1)}$ \\ 1) Fakultas Pertanian \\ Universitas Borneo Tarakan \\ Jalan Amal Lama Nomor 1, Tarakan \\ Email: ${ }^{1}$ dwulandari4@gmail.com
}

\begin{abstract}
ABSTRAK
Usahatani hortikultura khususnya buah-buahan di Indonesia selama ini hanya dipandang sebagai usaha sampingan yang sederhana serta ditanam di pekarangan atau areal sempit, penerapan teknik budidaya, dan penanganan pasca panen yang masih sederhana. Permintaan pasar terhadap buah baik dari pasar lokal maupun pasar ekspor yang menghendaki mutu tertentu, ukuran seragam dan pasokan buah yang berkesinambungan. Salah satu faktor yang mendukung keberhasilan usaha tani adalah aspek pemasaran.Aspek pemasaran berfungsi untuk meningkatkan nilai kegunaan suatu produk. Sebagai salah satu wilayah pengembangan buah mangga di wilayah Kalimantan Utara, Pulau Sebatik memiliki potensi strategis sebagai penghasil komoditi durian dan berbatasan dengan dengan wilayah negara Malaysia. Tujuan dari penelitian ini adalah menganalisis saluran pemasaran dan peran sistem informasi pasar pada tataniaga komoditas mangga di Desa Aji Kuning Kecamatan Sebatik Tengah. Metode yang digunakan dalam penelitian ini menggunaka dua elemen yaitu elemen informasi pasar dan manajemen informasi pasar dan dianalisis dengan menggunakan frekuensi distribusi relative menurut kategori jawaban. Hasil penelitian menunjukkan bahwa terdapat dua model pemasaran komoditi durian dan sistem informasi pasar yang terbentuk merupakan interaksi antara penawaran dan permintaan. Dan mayoritas responden menggunakan sistem informasi yang bersifat informal yaitu dari mulut ke mulut dan cenderung lebih mempercayai sumber informasi dari pedagang pengumpul.
\end{abstract}

Kata Kunci : Informasi, Mangga, Pasar, Pemasaran, Saluran

\begin{abstract}
Horticulture farming, especially fruits in Indonesia, has only been seen as a simple side business and planted in a yard or narrow area, applying cultivation techniques, and simple post-harvest handling. Market demand for fruit from both local markets and export markets that requires certain quality, uniform size and sustainable fruit supply. One of the factors that support the success of farming is the marketing aspect. The marketing aspect serves to increase the usefulness of a product. As one of the mango development areas As one of the mangrove development areas in the North Kalimantan region, Sebatik Island has strategic potential as a producer of durian commodities and borders with the territory of Malaysia. The purpose of this study is to analyze the marketing channel and the role of market information systems in mango commodity trading in the Aji Kuning Village, Central Sebatik Sub District. The method used in this study uses two elements namely market information elements and market information management and analyzed using relative distribution frequency according to the answer category. The results of the study show that there are two marketing models of mango commodities and the market information system that is formed is the interaction between supply and demand. And the majority of respondents use information systems that are informal, ie word of mouth and tend to trust the source of information from the collector.
\end{abstract}

Keywords: Information, Mangoes, Markets, Marketing, Channels 


\section{PENDAHULULUAN}

Usahatani hortikultura khususnya buahbuahan di Indonesia selama ini hanya dipandang sebagai usaha sampingan yang sederhana serta ditanam di pekarangan atau areal sempit, penerapan teknik budidaya, dan penanganan pasca panen yang masih sederhana. Permintaan pasar terhadap buah baik dari pasar lokal maupun pasar ekspor yang menghendaki mutu tertentu, ukuran seragam dan pasokan buah yang berkesinambungan. Oleh karena itu dalam rangka mengembangkan buah-buahan di Indonesia dan untuk meningkatkan daya saingnya baik di pasar lokal maupun pasar ekspor, pemerintah menggalangkan pembangunan pertanian bidang hortikultura dan strategi pemasarannya (Arifin et. al., 1997). Saat ini buah telah menjadi komoditas perdagangan internasional. Beberapa jenis buah unggulan Indonesia yang dapat bersaing di pasar internasional diantaranya adalah pisang, mangga, manggis, jeruk, salak, pepaya, nenas, rambutan, durian, semangka, nangka dan duku. Prospek agribisnis buahbuahan, khususnya durian, mangga dan rambutan.

Salah satu faktor yang mendukung keberhasilan usaha tani adalah aspek pemasaran.Aspek pemasaran berfungsi untuk meningkatkan nilai kegunaan suatu produk, hal ini juga berlaku terhadap usahatani durian salah satu pendukung keberhasilan usahatani durian adalah optimalnya aspek pemasaran yang dilakukan. Pemasaran komoditas pertanian khususnya hortikultura merupakan bagian yang paling lemah dalam mata rantai perekonomian. Hal ini berarti efisiensi dibidang pemasaran masih rendah sehingga kemungkinan untuk mempertinggi tingkat efisiensi masih besar (Mubyarto, 1995). Dalam aspek pemasaran banyak komponen-komponen yang mempengaruhi efisiensi pemasaran itu sendiri. Salah satu komponen tersebut adalah komponen informasi pasar. Informasi berbeda dengan data., (Davis dan Olson, 1985) informasi adalah data yang telah diproses dalam bentuk yang berarti bagi penerimanya dan memiliki nilai yang nyata atau yang di rasakan dalam pengambilan keputusan pada saat ini atau di masa yang akan datang. Informasi pasar tersebut akan menjadi sebuah sistem yang akan berpengaruh, Pada dasarnya sebuah sistem adalah suatu kumpulan dua atau lebih elemen seperti orang, benda ataupun konsep yang berhubungan satu dengan yang lainnya dalam mencapai suatu tujuan bersama. Sistem biasanya terbagi lagi dalam sub-sub sistem. Sistem akan bekerja baik bila semua sub sistem bekerja bersama-sama secara terpadu.

Nunukan sebagai merupakan salah satu wilayah pengembagan komoditi buah-buahan ini di Propinsi Kalimantan Utara.Komoditi unggulan yang di kembangkan oleh pemerintah Kabupaten Nunukan adalah komoditi buah yang diperkirakan diminati pasar, daya dukung agronominya memungkinkan dan mudah perawatannya. Salah satu tanaman unggulan di Kabupaten Nunukan adalah komoditi mangga yang banyak tumbuh khusus di Pulau Sebatik .Kondisi tersebut didukung oleh potensi lahan yang luas, dan banyak masyarakat yang membudidayakan mangga. Pulau Sebatik merupakan bagian Kabupaten Nunukan yang berupa pulau. Pulau ini terbagi dua dengan Malaysia dan berhadapan langsung dengan Kota Tawau. Posisinya yang berada di daerah perbatasan Indonesia - Malaysia menjadikan Pulau Sebatik sebagai daerah yang strategis dalam peta lalu lintas antar negara. Awalnya Kecamatan Sebatik merupakan salah satu dari lima kecamatan dari kabupaten Nunukan yang berdiri pada Tahun 1999 ini merupakan hasil pemekaran Kabupaten Bulungan dengan luas wilayah 104,42 km2 dan pada tahun 2006 Kecamatan Sebatik dimekarkan menjadi dua yaitu Kecamatan Sebatik dan Kecamatan Sebatik Barat sesuai dengan Peraturan Daerah Kabupaten Nunukan No. 03 Tahun 2006 tentang Pembentukan Kecamatan Sebatik Barat dan pada Tahun 2011 dimekarkan lagi menjadi lima yaitu Kecamatan Sebatik, Kecamatan Sebatik barat, Kecamatan Sebatik Timur, Kecamatan Sebatik Utara dan Kecamatan Sebatik Tengah sesuai Peraturan Daerah Kabupaten Nunukan No 25 Tahun 2011. Pulau Sebatik merupakan salah satu sentra penghasil komoditi buah-buahan khususnya durian dan 
seluruh hasil produksinya dijual ke wilayah Malaysia yaitu Kota Tawau.

Desa Aji Kuning Kecamatan Sebatik Tengah adalah salah satu Desa penghasil buah-buahan terbesar dan pada umumnya di jual ke Tawau (Malaysia) dengan pembayaran menggunakan mata uang Ringgit. Sistem informasi pasar adalah salah satu cara agar petani mengetahui harga komoditas hortikultura sebelum penentuan harga komoditas. Tujuan dari penelitian ini adalah menganalisis saluran pemasaran dan peran sistem informasi pasar pada tataniaga komoditas mangga di Desa Aji Kuning Kecamatan Sebatik Tengah.

\section{METODE PENELITIAN}

Penelitian ini di laksanakan di Kabupaten Nunukan Kecamatan Sebatik Tengah Desa Aji Kuning pada petani hortikultura khususnya buah-buahan, lokasi ini dipilih atas pertimbangan bahwa di daerah tersebut merupakan pintu gerbang antara Pulau Sebatik Tengah dan Tawau (Malaysia dan Indonesia. Pengumpulan Data dilakukan dengan Wawancara mendalam (in-depth interview), Eksplorasi dan studi berbagai dokumen dan bahan pustaka yang mendukung kegiatan penelitian ini.

Data dianalisis secara deskriptif dengan menggunakan distribusi frekuensi relative menurut kategori jawaban. Distribusi frekuensi relative ini digunakan untuk melihat bagiamana hubungan sistem informasi pasar dalam tataniaga buah-buahan di wilayah penelitian yaitu dengan menggambarkan sistem informasi pasar tataniaga buah-buahan, sistem tataniaganya dan hubungan kedua sistem tersebut.

\section{HASIL DAN PEMBAHASAN}

\section{A. Karakteristik Responden Petani}

Berdasarkan tabel 1 terlihat bahwa distribusi responden berdasarkan usia didapatkan hasil bahwa mayoritas berusia dibawah usia 50 tahun yaitu sekitar $76,7 \%$, dengan pendidikan masing-masing 46,5 lulusan SD, 33,3\% lulusan SMP dan 20\% lulusan SMA. Mayoritas responden memiliki luas lahan garapan berkisar 0 - 5 Ha yaitu sebesar $76,6 \%$ dengan status kepemilikan lahan sendiri. Melihat hasil tersebut, maka petani berdasarkan produkvitas pekerjaannya cukup tinggi karena tergolong usia produktif yaitu dibawah 50 tahun. Berdasarkan pola pikir dan cara pengambilan keputusan masih tergolong rendah dikarenakan pendidikan hanya sampai tingkat SD namun berdasarkan lama usahatani mayoritas responden petani memiliki usahatani lebih dari 20 tahun sehingga hal tersebut cukup berpengaruh terhadap kemampuannya dalam menjaga sinergis usahanya terhadap perubahan yang terjadi. Dan berdasarkan skala usahataninya tergolong cukup tinggi karena luasan lahan yang cukup besar yaitu lebih dari $2 \mathrm{Ha}$ dengan status kepemilikan lahan sendiri.

Tabel 1. Karakteristik Responden Petani di Desa Aji Kuning Kecamatan Sebatik Tengah

\begin{tabular}{|r|l|ll|}
\hline No & \multicolumn{1}{|c|}{ Komponen } & \multicolumn{2}{c|}{ Hasil } \\
\hline 1. & Tingkat Usia & $<50$ Tahun & $76,7,3 \%$ \\
& & $>50 T a h u n$ & $23,3 \%$ \\
\hline 2. & Tingkat Pendidikan & SD & $46,6 \%$ \\
& & SMP & 33,3 \\
& & SMA & $20 \%$ \\
\hline 3. & Luas Lahan Garapan & $<5 \mathrm{Ha}$ & $76,6 \%$ \\
& & $\geq 5 \mathrm{Ha}$ & $23,3 \%$ \\
\hline 4. & Status Lahan Garapan & Sendiri & $100 \%$ \\
& & Sewa & $-\%$ \\
\hline 5. & Lama Bertani & $<20 T a h u n$ & $63,3 \%$ \\
& & $\geq 20 T a h u n$ & $26,6,3 \%$ \\
\hline
\end{tabular}




\section{B. Pemasaran Komoditi Mangga di Desa Aji Kuning Kecamatan Sebatik Tengah}

Saluran pemasaran merupakan jalur yang di lalui komoditas buah-buahan di Desa Aji Kuning Kecamatan Sebatik Tengah sampai ke konsumen akhir. Sistem saluran yang di lakukan oleh produsen dan pengumpul secara langsung dan tidak lansung. Yang dimana saluran pemasaran langsung itu tidak menggunakan perantara sedangkan sistem saluran tidak langsung itu menggunakan perantara dalam salurannya. Saluran pemasaran komoditi mangga di Desa Aji Kuning Kecamatan Sebatik Tengah dapat dilihat pada Gambar 1.

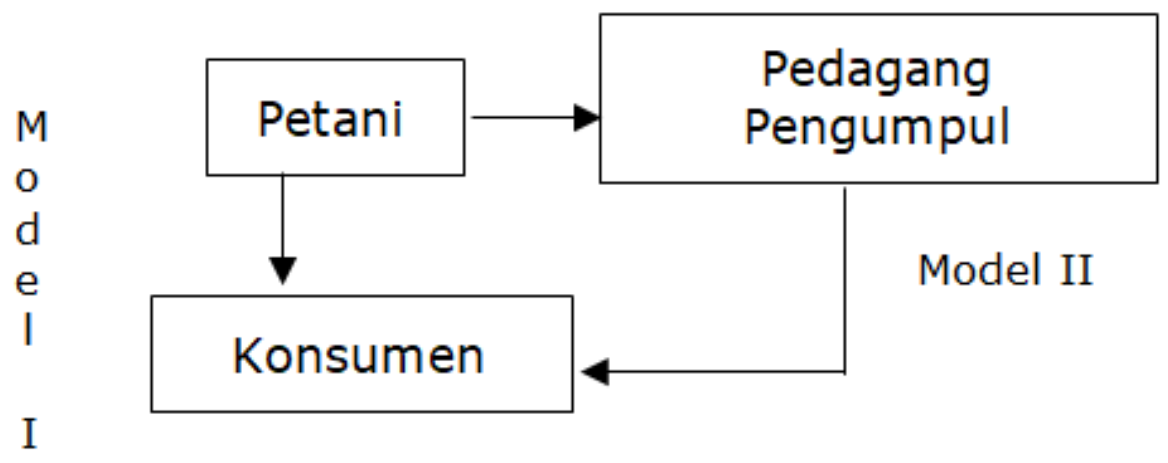

\section{Gambar 1. Model Pemasaran Komoditi Mangga di Desa Aji Kuning Kecamatan Sebatik Tengah 2016}

Dari Gambar 1 terlihat bahwa terdapat 2 bentuk saluran pemasaran komoditi durian di Desa Aji Kuning yaitu :

a) Saluran pemasaran 1 , produsen atau petani memasarkan hasil produksinya kepada konsumen akhir yang pada umumnya adalah masyarakat atau tetangga maupun di pasar terdekat dengan cara masyarakat atau warga yang datang ke pasar di harihari tertentu. Terdapat pula petani atau produsen yang langsung membawa hasil produksinya ke Tawau dengan permintaan sesuai dengan kesepakatan antara produsen dan konsumen akhir. Dalam hal ini produsen atau petani dapat menghemat biaya transportasi. Hal ini sesuai dengan pendapat Hanafiah dan Saefuddin (1986) bahwa semakin jauh daerah konsumen terhadap daerah produksi, akan menambah besar biaya tataniaga.

b) Saluran pemasaran 2, produsen (petani) menjual hasil produksinya kepada pedagang pengumpul, yang ada di sekitar Desa Aji Kuning. Pedagang pengumpul akan menerima permintaan dari konsumen yang berada di Tawau Malaysia, dengan jumlah yang sesuai dengan permintaan, dan ketika jumlah permintaan belum mencukupi ini adalah bagian dari tanggungjawab pedagang pengumpul untuk bisa memenuhi permintaan tersebut. Dalam saluran ini, penentuan harga dilakukan oleh pedangan pengumpul dan petani hanya menerima harga yang sudah ditentukan.

Proses penjualannya yaitu dengan cara pedagang pengumpul membawa ke Tawau Malaysia dengan menggunakan transportasi kapal barang, biasanya pedagang pengumpul mempunyai kapal barang sendiri sehingga dapat memperkecil biaya transportasi pengangkutan. Pedagang pengumpul menjualnya kepada konsumen akhir dengan ketetapan harga yang telah di tentukan oleh pedagang pengumpul itu sendiri. Berdasarkan Tabel 2 dapat di ketahui $37 \%$ petani menggunakan saluran pemasaran I di mana petani langsung menjual komoditas hortikultura tersebut di Tawau (Malaysia). Sedangkan saluran pemasaran II dapat di ketahui 63\% menggunakan saluran pemasaran di mana petani lebih memilih untuk menjual kepada pengumpul dengan harga yang telah di tentukan, proses penjualan ini juga tidak mengeluarkan biaya karena pedagang pengumpul yang akan mendatangi produsen sehingga pengeluaran biaya untuk produsen semakin berkurang. 
Tabel 2. Jenis Saluran Pemasaran dan Jumlah Petani Responden di Desa Aji Kuning Kecamatan Sebatik Tengah 2017

\begin{tabular}{|c|c|c|c|}
\hline No & Saluran Pemasaran & Jumlah Petani & Presentase (\%) \\
\hline 1 & Saluran I & 11 & 37 \\
\hline 2 & Saluran II & 19 & 63 \\
\hline & Jumlah & $\mathbf{3 0}$ & $\mathbf{1 0 0}$ \\
\hline
\end{tabular}

\section{Sumber : Data Primer diolah, 2016}

Desa Aji Kuning, Kecamatan Sebatik Tengah dan Tawau merupakan dua daerah dengan negara yang berbeda, tetapi perbedaan itu tidak menjadi penghambat untuk melakukan perdagangan di antara warga dari kedua negara itu. Kondisi tersebut dikarenakan Tawau merupakan daerah yang tidak asing lagi bagi warga Sebatik Tengah khususnya Desa aji Kuning dan sudah di kenal sejak adanya penduduk yang bermukim di Desa Aji Kuning. Kota Tawau berperan sebagai daerah tujuan penjualan hasil usahatani dan penyedia kebutuhan sehari-hari masyarakat di wilayah Pulau Sebatik.

Dengan wilayah Kota Tawau sistem transaksi perdagangan menggunakan dua jenis mata uang yang di gunakan terdiri atas dua jenis, yaitu ringgit Malaysia (RM) dan rupiah (Rp). Kecuali di kantor-kantor pemerintahan dan ataupun perusahaan swasta skala nasional seperti Kantor Pegadaian dan bank tetap mewajibkan transaksi dengan menggunakan mata uang ringgit Malaysia (RM) . Kondisi tersebut memberikan peluang usaha bidang penukaran uang.

Kondisi yang mendukung proses perdagangan antar masyarakat Pulau Sebatik dan Tawau juga didukung oleh kesamaan etnis masyarakat yang ada. Pada umumnya mitra dagang yang ada di Tawau juga pendatang yang berasal dari Sulawesi Selatan yang sudah menjadi warga negara Malaysia di Tawau.
Kesamaan etnis dengan warga Desa Aji Kuning, Kecamatan Sebatik Tengah yang juga berasal dari Sulawesi Selatan menjadi modal dalam membangun jaringan perdagangan hortikultura di antara mereka karena selain menggunakan bahasa Melayu ataupun bahasa Indonesia, para pelaku usaha ini dapat menggunakan bahasa Bugis sebagai alat komunikasi untuk bertransaksi.

\section{Analisis Informasi Pasar Pada Pemasaran Komoditi Mangga}

Dalam proses pemasaran setiap lembaga yang terlibat di dalamnya memerlukan informasi pasar dan harga. Informasi pasar diperlukan oleh mereka untuk mengetahui tentang kondisi pasar dan harga pasar. Petani mangga melakukan fungsi fasilitas yang berupa informasi pasar dan harga karena petani memerlukan informasi harga pasar yang berlaku sehingga bisa menentukan harga jual. Adapun di tingkat pedagang pengumpul dan petani itu sendiri informasi pasar dan harga sangat diperlukan. Informasi pasar diperlukan untuk mengetahui secara pasti mengenai kapan musim panen terjadi dan dimana lokasi panen, sehingga dari infomasi tersebut jauh hari sebelumnya pedagang pengumpul akan mempersiapkan segala sesuatunya untuk mendatangi petani di daerah yang sedang panen. Harga yang ditentukan oleh pedagang sesuai dengan biaya yg di keluarkan. 
Tabel 3. Sistem Informasi Yang Digunakan Petani Responden di Desa Aji Kuning

\begin{tabular}{|c|c|c|c|}
\hline No & Komponen & Hasil & \\
\hline 1. & $\begin{array}{l}\text { Sumber Informasi yang } \\
\text { digunakan }\end{array}$ & $\begin{array}{l}\text { Kelompok tani } \\
\text { Pedagang Pengumpul }\end{array}$ & $\begin{array}{c}53,33 \% \\
46,6 \%\end{array}$ \\
\hline 2. & $\begin{array}{lcl}\text { Jumlah } & \text { Informasi } \\
\text { dimanfaatkan Responden }\end{array}$ & $\begin{array}{l}\text { Satu sumber Informasi } \\
\text { Dua Sumber Informasi }\end{array}$ & $\begin{array}{l}66,7 \% \\
33,3 \%\end{array}$ \\
\hline 3. & Saat Mengetahui Harga & $\begin{array}{l}\text { Sebelum Penjualan } \\
\text { Saat penjualan } \\
\text { Sesudah penjualan }\end{array}$ & $100 \%$ \\
\hline 4. & $\begin{array}{l}\text { Cara Mencari informasi } \\
\text { terpercaya }\end{array}$ & $\begin{array}{l}\text { Kelompok Tani } \\
\text { Pedagang Pengumpul }\end{array}$ & $\begin{array}{l}33,3 \% \\
66,7 \%\end{array}$ \\
\hline 5. & Cara Mengelola Informasi & $\begin{array}{l}\text { Memperoleh dari media } \\
\text { cetak/elektronik dan } \\
\text { dicatat } \\
\text { Memperoleh dari sumber } \\
\text { informasi dan dicatat } \\
\text { Memperoleh dari sumber } \\
\text { informasi dan dihapal }\end{array}$ & $\begin{array}{r}-\% \\
100 \% \\
-\%\end{array}$ \\
\hline
\end{tabular}

\section{Sumber : Data Primer Diolah, 2016.}

Aspek sistem informasi yang digunakan oleh responden di lokasi penelitian dapat dilihat di Tabel 3. Berdasarkan data terlihat bahwa mayoritas responden menggunakan satun sumber informasi yang berasal dari kelompok tani. Hal ini menunjukkan bahwa masih terbatasnya akses dan kecukupan informasi pasar dari pemasaran usahatani mereka. Namun berdasarkan persepsi petani sumber informasi terpercaya mereka justru dari pedagang pengumpul. Menurut mereka informasi pasar seperti harga dan jumlah kebutuhan pasar akan komoditi durian dipasar lebih dapat dipercaya jika berasal dari pedagang pengumpul. Adapun metode mengelola informasi mayoritas responden menggunakan metode dicatat dengan alasan bahwa ketika petani mempunyai pegangan cacatan akan lebih mudah tanpa harus mencari informasi yang berulang-ulang.

\section{KESIMPULAN}

Kesimpulan dari penelitian ini adalah :

1. Terdapat 2 saluran pemasaran komoditi manga di Desa Aji Kuning Kecamatan Sebatik Tengah yaitu:

a. Produsen - Konsumen

b. Produsen - Pedagang Pengumpul Konsumen
2. Peran informasi pasar dalam hal ini adalah sangat besar dalam penentuan harga komoditi mangga yang akan di jual ke Tawau (Malaysia). Adapun Sumber informasi pasar yang telah di gunakan oleh responden ada 2 yaitu dari kelompok tani dan pedagang pengumpul, sedangkan ada 2 jenis informasi yang di manfaatkan responden yaitu satu sumber informasi dan dua informasi. Saat responden mengetahui perubahaan harga jual komoditas buahbuahan adalah sebelum penjualan di laksanakan, keaktifan responden mencari informasi lebih mayoritas adalah pedagang pengumpul dengan mencari informasi dan catat.

\section{DAFTAR PUSTAKA}

Aak. 1997. Budidaya Durian. Yogyakarta: Penerbit Kanisius

Bappeda Kab. Nunukan. 2010. Profil Kabupaten Nunukan 2010. Nunukan: Bappeda Kabupaten Nunukan

Badan Pusat Statistik, 1999. Kabupaten Nunukan Dalam Angka 1999. Nunukan: BPS Kabupaten Nunukan

Bappeda Kabupaten Nunukan dengan BPS Kabupaten Nunukan, 2002, Kabupaten Nunukan dalam Angka Tahun 2002, BPS, Nunukan 
Kotler, P, 1987. Dasar - Dasar Pemasaran. PT. Midas Surya Grafindo. Jakarta

Kotler, Philip. 1996. Marketing. Jilid 1 (Edisi Bahasa Indonesia Dari Marketing Essentials). Diterjemahkan Oleh : Herujati Purwoto. Jakarta: Erlangga

Sudiyono, A. 2001. Pemasaran Pertanian. Penerbit Universitas Muhammadiyah Malang. (UMM Press). Malang

Saefuddin dan Hanafiah. 1983. Siklus Dan Skala Pemasaran. Jakarta

Soehardi Sigit. 1992. Marketing Praktis. Penerbit armurrita: Yogyakarta Soekartawi. 2002. Prinsip Dasar Manajement Pemasaran Hasil-Hasil Pertanian. Raja grafindo. Jakarta

Stanton, W.J. 1993. Prinsip Pemasaran Edisi Ketujuh. Erlangga. Jakarta
Sudiyono, A, 2004.Pemasaran Pertanian. UMM Press, Malang

Sudiyono. A, 2002.Pemasaran Pertanian. UMM Press, Malang

Sugiyono, (2008). Metodologi Penelitian Bisnis. Bandung: Alfabeta

Sugiyono. (2010). Statistika Untuk Penelitian. Bandung: Alfabeta

Swastha, Basu, 1999, "Loyalitas Pelanggan : Sebuah Kajian Konseptual Sebagai Panduan bagi Peneliti", Jurnal Ekonomi dan Bisnis Indonesia, Vol.14, No.3, hal.73-88, Yogayakarta: Universitas Gajah Madah

Swasta, B. dan Handoko, H., 2000. Manajemen Pemasaran : Analisis Perilaku Konsumen. Edisi Ketiga. Penerbit Liberty. Yogyakarta Swastha, B., 1998. Pengantar Bisnis Modern. Liberty, Yogyakarta 
